\title{
Aspectos psicossociais que interferem no rendimento de modalidades desportivas coletivas
}

Psychosocial aspects that influence performance in team sports

\author{
Clara Maria Silvestre Monteiro de Freitas \\ João Manuel de Farias Junior ${ }^{1,2}$ \\ Aloísio Bezerra Sandes Junior ${ }^{1}$ \\ Carlos Augusto Cardoso Kucera ${ }^{1}$ \\ Rebeca Rodrigues de Melo \\ Ana Carolina Leão ${ }^{1}$ \\ Ana Elizabeth Vieira da Cunha
}

1 Universidade de Pernambuco. Escola Superior de Educação Física. Grupo de Estudos e Pesquisa Socio-culturais e o Indivíduo em Educação Física e Desporto. Laboratório de Prática Desportiva e Lazer. Recife, PE, Brasil.

2 Universidade de Pernambuco. Escola Superior de Educação Física.

Programa Institucional de Bolsa de Iniciação Científica PIBIC / CNPq. Recife, PE. Brasil.

Recebido em 08/01/08 Revisado em 07/04/08 Aprovado em 10/10/08
Resumo - Esta investigação objetiva discutir os aspectos psicossociais que inibem ou favorecem o desempenho, apresentando sugestões de treinamento com interferências favoráveis à performance; e ainda, discutir o rendimento desportivo sob o prisma qualidade de vida. Participaram do estudo descritivo 103 atletas de rendimento de modalidades coletivas, de cinco instituições da cidade do Recife-Pernambuco. Os questionários foram o WHOQOL, o FISSB e FISS-J. Os resultados encontrados foram: o espírito de equipe é muito importante para vencer $(98,0 \%)$; satisfação em trabalhar em equipe $(95,0 \%)$. No tocante às situações inibidoras de desempenho, os índices mais representativos foram: arbitragem prejudicial (81,4\%); perder jogo praticamente ganho (75,7\%). No âmbito da qualidade de vida, os indicadores relevantes foram: minha vida tem sentido (92,2\%); avaliação de uma boa qualidade de vida $(89,2 \%)$. Essas categorias apontaram a necessidade do treinamento desportivo sob a ótica humanista, interagindo a tecnologia do treinamento e as necessidades sociopsicológicas, potencializando as qualidades físicas, técnicas e táticas dos atletas.

Palavras-chave: Impacto psicossocial; Desempenho atlético, Qualidade de vida.

Abstract - The objective of the present investigation was to discuss the psychosocial factors that inhibit or stimulate performance, presenting training suggestions that include interventions to enhance performance. In addition, sports performance was discussed from the perspective of quality of life. A descriptive quantitative-cum-qualitative field method was employed. A total of 103 athletes engaged in team sports from five institutions in the city of Recife, Pernambuco, participated in the study. The WHOQOL, FISSB and FISS-J questionnaires were used. The following results were obtained: "team spirit is extremely important for winning" (98.0\%) and "satisfaction in working as a team" (95.0\%). With respect to situations that inhibit performance, the most representative findings were "poor refereeing" (81.4\%) and "losing a game practically already won" (75.7\%). From the quality of life perspective, the main indicators were "my life is meaningful" (92.2\%) and "a good quality of life rating" (89.2\%). These analytical categories indicate the need for sports training to be carried out from a humanistic standpoint in which the training technology interacts with sociopsychological needs, thus potentiating the physical, technical and tactical qualities of the athletes.

Key words: Psychosocial Impact; Athletic Performance; Quality of life. 


\section{INTRODUÇÃO}

A busca por melhores resultados no meio desportivo é um fenômeno que ocorre mediante a relação de múltiplas variáveis integradas num contexto de dimensões diversas e complexas. Estudos ${ }^{1-11}$ apontam que aspectos psicossociais, tais como motivação, autoconfiança, ansiedade, concentração, medo do erro, estresse, emoção e coesão de grupo, exercem influências significativas nas performances dos atletas.

Da mesma forma, indicadores de qualidade de vida são importantes para o desporto, podendo afetar o desempenho e influenciar nos resultados obtidos em competições. Para que não ocorram influências negativas, a dimensão psicossocial necessita ser considerada ao se estruturar o treinamento, pois se percebe que alguns atletas sofrem conseqüências relevantes diante da pressão psíquica e social que o jogo exerce ${ }^{12-16}$.

No contexto de modalidades desportivas coletivas, duas ciências ganham significativos valores: a Sociologia do Desporto que tem por objeto o estudo das interações sociais e a Psicologia Desportiva está ligada aos estudos dos fenômenos psíquicos que norteiam o comportamento individual e coletivo. Logo, a Psicossociologia do Desporto tem por objeto observar, analisar e discutir o intercâmbio de comportamento mantido entre o individual, o grupal e o institucional desportivo, tentando responder a um conjunto de fenômenos interativos e psíquicos que influenciam os desportistas no desempenho de seus papéis e funções dentro desse universo ${ }^{17}$.

Diante desse cenário, esse estudo objetivou investigar os aspectos psicossociais relacionados às competições, rotinas de treino e à qualidade de vida dos atletas de rendimento de modalidades desportivas coletivas. Especificamente, buscou-se estabelecer relações entre os aspectos psicossociais que favorecem e/ou inibem a performance com possibilidades de intervenções no treinamento desportivo.

\section{PROCEDIMENTOS METODOLÓGICOS}

O delineamento da pesquisa foi de cunho descritivo, baseado na premissa de que as práticas podem ser melhoradas por meio da análise e descrição objetivas e completas de determinado fenômeno ${ }^{18}$.

Os participantes do estudo foram 103 atletas, da cidade do Recife - Pernambuco, das modalidades Futsal, Handebol, Basquetebol, Voleibol e Hóquei, sendo 52 mulheres e 51 homens. Os atletas eram oriundos do Clube Náutico Capibaribe, Sport Club do Recife, Universidade de Pernambuco (UPE),
Universidade Católica de Pernambuco (UNICAP), Universidade Maurício de Nassau e Universidade Salgado de Oliveira (UNIVERSO).

$\mathrm{Na}$ coleta de dados, foram utilizados três instrumentos. $\mathrm{O}$ primeiro foi uma ficha de identificação, contendo dados sobre a faixa etária, gênero, nível de competição mais alto que o atleta participou e tempo de prática em sua modalidade (tabela 1). Na construção do segundo instrumento foram utilizados dois questionários de De Rose Junior ${ }^{1,2}$, o primeiro denominado Formulário para Identificação de Situações de "Stress" em Basquetebol (FISSB), para atletas e, o segundo, o Formulário para Identificação de Situações de "Stress" em Jogo (FISS-J). Assim, foi realizada uma composição entre esses dois questionários, ambos relativos ao estresse (tabela 3), adaptando-os à realidade objeto do estudo, sendo acrescidas questões que envolviam aspectos psicossociais, tais como: aspectos sociais (tabela 2) ansiedade (tabela3) autoconfiança, concentração, auto-estima, treino mental, motivação e pensamentos negativos (tabela 4). Por se tratar de um questionário adaptado, este passou pela fase de testagem da reprodutibilidade, que indicou a viabilidade e confiabilidade de sua aplicação. $O$ terceiro instrumento foi a versão simplificada do questionário da Organização Mundial de Saúde (OMS) denominado WHOQOL (tabela 5), que tratou das questões sobre qualidade de vida. As informações foram coletadas através de entrevista estruturada.

O presente estudo atendeu às determinações éticas que envolvem seres humanos, sendo previamente aprovado pelo Comitê de Ética da Universidade de Pernambuco. Só foram admitidos ao estudo aqueles sujeitos que assinaram o Termo de Consentimento Livre e Esclarecido (Processo 093/2006).

A análise dos dados foi apresentada sob a forma das freqüências absolutas e relativas e foram apreciados na ótica do gênero. Os resultados foram analisados e discutidos com base na escala Likert, compreendida em 5 níveis, dos quais 1 discordo completamente, 2 concordo pouco, 3 concordo parcialmente, 4 concordo bastante, 5 concordo completamente. Na apresentação dos resultados, e com base no procedimento metodológico adotado por De Rose Jr. ${ }^{3}$, foi objeto de análise e discussão a soma dos resultados relativos aos níveis $4 \mathrm{e}$ 5. Por último, os dados passaram por um tratamento estatístico, utilizando-se o pacote SPSS (Statistical Package for Social Sciences) 13.0 for Windows.

\section{RESULTADOS}

A tabela 1 apresenta um equilíbrio no número de participantes quanto ao quesito gênero, dos quais 51 
Tabela 1. Perfil da amostra quanto ao gênero, faixa etária e nível competitivo - 2007.

\begin{tabular}{|c|c|c|c|c|c|c|c|c|c|c|}
\hline \multirow{3}{*}{$\begin{array}{l}\text { Indicadores } \\
\text { Gênero }\end{array}$} & \multicolumn{10}{|c|}{ Modalidades } \\
\hline & \multicolumn{2}{|c|}{ Hóquei } & \multicolumn{2}{|c|}{ Futsal } & \multicolumn{2}{|c|}{ Basquetebol } & \multicolumn{2}{|c|}{ Voleibol } & \multicolumn{2}{|c|}{ Handebol } \\
\hline & $f$ & $\%$ & $f$ & $\%$ & $f$ & $\%$ & $f$ & $\%$ & $f$ & $\%$ \\
\hline Masculino & 11 & 100 & 10 & 62,5 & 16 & 57,1 & 14 & 53,8 & 0 & 0 \\
\hline Feminino & 0 & 0 & 06 & 37,5 & 12 & 42,9 & 12 & 46,2 & 22 & 100 \\
\hline Faixa Etária & $f$ & $\%$ & $\mathrm{f}$ & $\%$ & $f$ & $\%$ & $\mathrm{~F}$ & $\%$ & $\mathrm{f}$ & $\%$ \\
\hline De 16 a 20 anos & 08 & 72,7 & 09 & 60 & 05 & 18,5 & 13 & 50 & 10 & 45,5 \\
\hline De 21 a 25 anos & 02 & 18,2 & 03 & 20 & 12 & 44,4 & 09 & 34,6 & 07 & 31,8 \\
\hline De 26 a 30 anos & 0 & 0 & 02 & 13,3 & 09 & 33,3 & 04 & 15,4 & 5 & 22,7 \\
\hline De 31 a 35 anos & 01 & 9,1 & 01 & 6,7 & 0 & 0 & 0 & 0 & 0 & 0 \\
\hline 36 anos e mais & 0 & 0 & 0 & 0 & 01 & 3,7 & 0 & 0 & 0 & 0 \\
\hline Nível de Competição & $f$ & $\%$ & $f$ & $\%$ & $f$ & $\%$ & $f$ & $\%$ & $f$ & $\%$ \\
\hline Municipal & 0 & 0 & 02 & 12,5 & 01 & 3,6 & 01 & 3,8 & 01 & 4,5 \\
\hline Estadual & 0 & 0 & 02 & 12,5 & 01 & 3,6 & 02 & 7,7 & 05 & 22,7 \\
\hline Nacional & 06 & 54,5 & 09 & 64,3 & 22 & 78,6 & 21 & 80,8 & 16 & 72,7 \\
\hline Sul-americano & 02 & 18,2 & 01 & 7,1 & 01 & 3,6 & 0 & 0 & 0 & 0 \\
\hline Pan-americano & 0 & 0 & 0 & 0 & 01 & 3,6 & 0 & 0 & 0 & 0 \\
\hline Mundial & 03 & 27,3 & 0 & 0 & 02 & 7,1 & 02 & 7,7 & 0 & 0 \\
\hline
\end{tabular}

Tabela 2. Indicadores sociais dos atletas segundo gênero - 2007.

\begin{tabular}{|c|c|c|c|c|c|c|}
\hline \multirow{2}{*}{$\begin{array}{l}\text { Indicadores } \\
\text { Aspectos Sociais }\end{array}$} & \multicolumn{2}{|c|}{ Total } & \multicolumn{2}{|c|}{ Masculino } & \multicolumn{2}{|c|}{ Feminino } \\
\hline & $\mathrm{f}$ & $\%$ & $\mathrm{f}$ & $\%$ & f & $\%$ \\
\hline 1. Competir com outras pessoas é socialmente agradável. & 79 & 77,4 & 41 & 80,4 & 38 & 74,5 \\
\hline 2. É afetivamente agradável treinar com os meus companheiros de equipe. & 95 & 92,2 & 48 & 94,1 & 47 & 90,4 \\
\hline 3. Gosto de trabalhar em equipe. & 96 & 95 & 48 & 96 & 48 & 94,1 \\
\hline 4. Penso que o "espírito de equipe" é importante para alcançar vitórias. & 101 & 98 & 49 & 96,1 & 52 & 100 \\
\hline $\begin{array}{l}\text { 5. Companheiro (a) egoísta é um fator que provoca queda de desempenho } \\
\text { da equipe. }\end{array}$ & 79 & 77,5 & 35 & 68,6 & 44 & 86,3 \\
\hline $\begin{array}{l}\text { 6. Normalmente cumprimento meus adversários após o término da partida, } \\
\text { independente do resultado da mesma. }\end{array}$ & 87 & 84,4 & 44 & 86,2 & 43 & 82,7 \\
\hline $\begin{array}{l}\text { 7. Costumo encorajar os meus companheiros de equipe, independente das } \\
\text { circunstâncias. }\end{array}$ & 88 & 85,4 & 46 & 90,2 & 42 & 80,7 \\
\hline $\begin{array}{l}\text { 8. Tive/Tenho pessoas em minha vida que ajudam a me manter treinando } \\
\text { (Parentes, treinador, amigos, cônjuge). }\end{array}$ & 76 & 74,5 & 35 & 68,7 & 41 & 80,4 \\
\hline
\end{tabular}

eram do gênero masculino e 52 do gênero feminino. No que diz respeito à faixa etária, a média alcançada foi 22,14 (dp = 4,48). E no tocante ao nível de competição, foi constatado que $67,8 \%$ dos atletas haviam participado de competições nacionais e 11,6\% disputaram competições sul-americanas, pan-americanas ou mundiais, totalizando $79,4 \%$ dos atletas com rendimento reconhecidamente elevado.

A tabela 2 apresenta situações referentes aos aspectos sociais no meio desportivo, revelando algumas questões significativas expressas nas assertivas o espirito de equipe é importante para alcançar vitórias (98\%) e o gosto de trabalhar em equipe (95\%). Essas são características essenciais para o bom andamento das atividades realizadas em grupo e, principalmente, quando esse grupo divide objetivos em comum.
A tabela 3 contempla os dados referentes ao estresse e à ansiedade. Nesse aspecto, viu-se que a arbitragem prejudicial $(81,4 \%)$ e perder o jogo praticamente ganho $(75,7 \%)$ são agentes estressores. No que diz respeito à ansiedade, o início do jogo foi o primeiro fator citado por $60,8 \%$ dos atletas.

Os dados contidos na tabela 4 forneceram informações acerca de aspectos psicossociais que apresentam fortes relações entre si. Nesse cenário, a autoconfiança foi percebida na assertiva tenho confiança nas minhas habilidades atléticas (79,6\%), como também nos momentos decisivos, sinto-me mais confiante para agir $(64,1 \%)$. A concentração foi um ponto forte desses atletas, demonstrada na baixa representatividade da assertiva a torcida influencia para me desconcentrar durante o jogo (5,8\%). Na variável treino mental, a 
Tabela 3. Indicadores de estresse e ansiedade segundo gênero - 2007.

\begin{tabular}{|c|c|c|c|c|c|c|}
\hline \multirow{2}{*}{$\begin{array}{l}\text { Indicadores } \\
\text { 1. Estresse }\end{array}$} & \multicolumn{2}{|c|}{ Total } & \multicolumn{2}{|c|}{ Masculino } & \multicolumn{2}{|c|}{ Feminino } \\
\hline & f & $\%$ & f & $\%$ & f & $\%$ \\
\hline 1.1 Errar em momentos decisivos, estressa-me. & 73 & 71,5 & 32 & 62,8 & 41 & 80,4 \\
\hline 1.2 Cometer erros que causem a derrota da equipe é um forte fator de estresse. & 68 & 66 & 29 & 56,9 & 39 & 75 \\
\hline 1.3 Repetir os mesmos erros, estressa-me. & 74 & 73,3 & 29 & 58 & 45 & 88,2 \\
\hline 1.4 Tenho medo de errar nos momentos decisivos. & 41 & 40,2 & 14 & 27,4 & 27 & 52,9 \\
\hline 1.5 Companheiro (a) que não se esforça causa-me estresse. & 69 & 67 & 31 & 60,8 & 38 & 73,1 \\
\hline 1.6 Companheiro (a) que reclama muito causa-me estresse. & 64 & 62,8 & 31 & 62 & 33 & 63,5 \\
\hline 1.7 Perder jogo praticamente ganho é algo que frustra-me e estressa-me bastante. & 78 & 75,7 & 37 & 72,6 & 41 & 78,8 \\
\hline 1.8 Arbitragem prejudicial a mim e/ou a minha equipe é estressante/irritante. & 83 & 81,4 & 36 & 70,6 & 47 & 92,1 \\
\hline $\begin{array}{l}1.9 \text { É estressante conviver com o técnico que só enxerga o lado negativo e não } \\
\text { reconhece os esforços dos seus jogadores. }\end{array}$ & 75 & 73,5 & 33 & 64,7 & 42 & 82,3 \\
\hline 2. Ansiedade & f & $\%$ & f & $\%$ & f & $\%$ \\
\hline 2.1 Antes de competir, meu coração bate mais rápido que o normal. & 55 & 53,4 & 22 & 42,5 & 33 & 63,5 \\
\hline 2.2 Sinto ansiedade enquanto espero o início do jogo. & 62 & 60,8 & 27 & 52,9 & 35 & 68,7 \\
\hline $\begin{array}{l}\text { 2.3 Procuro não pensar na minha atuação durante o dia que precede o jogo ( } 24 \\
\text { hs anteriores ao jogo). }\end{array}$ & 14 & 13,6 & 8 & 15,7 & 6 & 11,5 \\
\hline
\end{tabular}

Tabela 4. Indicadores psicossociais dos atletas segundo gênero - 2007.

\begin{tabular}{|c|c|c|c|c|c|c|}
\hline \multirow{2}{*}{$\begin{array}{l}\text { Indicadores } \\
1 \text {. Autoconfiança }\end{array}$} & \multicolumn{2}{|l|}{ Total } & \multicolumn{2}{|c|}{ Masculino } & \multicolumn{2}{|c|}{ Feminino } \\
\hline & $\mathrm{f}$ & $\%$ & f & $\%$ & f & $\%$ \\
\hline 1.1 Nos momentos decisivos, sinto-me mais confiante para agir. & 66 & 64,1 & 41 & 80,4 & 25 & 48,1 \\
\hline 1.2 Tenho muita confiança nas minhas capacidades e habilidades atléticas. & 82 & 79,6 & 44 & 86,2 & 38 & 71,2 \\
\hline $\begin{array}{l}1.3 \text { Geralmente consigo manter-me confiante, mesmo durante as minhas } \\
\text { piores atuações. }\end{array}$ & 45 & 43,7 & 29 & 56,8 & 16 & $30, \varepsilon$ \\
\hline 2. Concentração & f & $\%$ & f & $\%$ & f & $\%$ \\
\hline 2.1 A torcida influencia fortemente para me desconcentrar durante o jogo. & 6 & 5,8 & 3 & 5,9 & 3 & 5,7 \\
\hline 3. Auto-estima & f & $\%$ & f & $\%$ & f & $\%$ \\
\hline 3.1 Ficar atrás no placar afeta a minha auto-estima. & 9 & 8,8 & 5 & 9,8 & 4 & 7,8 \\
\hline 4. Emoção & f & $\%$ & f & $\%$ & f & $\%$ \\
\hline $\begin{array}{l}\text { 4.1 Expresso minhas emoções quando sou bem sucedido em determinados } \\
\text { momentos do jogo desportivo. }\end{array}$ & 74 & 71,9 & 36 & 70,5 & 38 & 73 \\
\hline 5. Treino Mental & f & $\%$ & f & $\%$ & f & $\%$ \\
\hline $\begin{array}{l}\text { 5.1 Procuro reviver mentalmente momentos vitoriosos da minha carreira } \\
\text { para me motivar a competir. }\end{array}$ & 75 & 72,8 & 43 & 84,3 & 32 & 61,6 \\
\hline 5.2 Costumo conversar comigo mesmo durante o jogo. & 61 & 59,8 & 30 & 58,8 & 31 & 60,8 \\
\hline 5.3 Antes da competição treino mentalmente o que planejo fazer no jogo. & 68 & 66 & 33 & 64,8 & 35 & 67,3 \\
\hline 6. Motivação & f & $\%$ & f & $\%$ & f & $\%$ \\
\hline $\begin{array}{l}\text { 6.1 Trabalhar com técnico (a) que só critica é desmotivante e prejudica } \\
\text { minhas atuações. }\end{array}$ & 53 & 51,5 & 24 & 47 & 29 & 55,7 \\
\hline 6.2 Ficar à frente no placar é algo motivador para ganhar o jogo. & 76 & 73,8 & 41 & 80,4 & 35 & 67,3 \\
\hline 6.3 Falta-me motivação para treinar. & 8 & 7,8 & 6 & 12 & 2 & 3,8 \\
\hline 7. Pensamentos Negativos & f & $\%$ & $f$ & $\%$ & f & $\%$ \\
\hline 7.1 Costumo pensar e reviver os erros que cometi numa partida. & 57 & 55,3 & 26 & 51 & 31 & 59,6 \\
\hline
\end{tabular}

afirmativa antes da competição treino mentalmente o que planejo fazer no jogo (66\%) compreende um indicador que reforça as características de desportistas competitivos. Quanto à motivação, ficar à frente no placar é algo que motiva os atletas (73,8\%). Apenas $7,8 \%$ revelaram que falta motivação para treinar.

Os resultados apresentados na tabela 5 trouxeram algumas evidências sobre a qualidade de vida dos atle- tas. As evidências mais representativas foram: minha vida tem sentido (92,2\%); avaliação de uma boa qualidade de vida (89,2\%) e satisfação com o apoio recebido dos amigos (82,5\%). Aspectos esses também preconizados pelo instrumento pentáculo do bem estar ${ }^{19}$. Sob este prisma, os atletas que não se enquadram nos mínimos parâmetros de uma vida saudável, estão propensos a não conseguir êxito no decorrer da sua carreira. 
Tabela 5. Indicadores de qualidade de vida dos atletas segundo gênero.

\begin{tabular}{|c|c|c|c|c|c|c|}
\hline \multirow{2}{*}{$\begin{array}{l}\text { Indicadores } \\
\text { Qualidade de Vida }\end{array}$} & \multicolumn{2}{|c|}{ Total } & \multicolumn{2}{|c|}{ Masculino } & \multicolumn{2}{|c|}{ Feminino } \\
\hline & f & $\%$ & f & $\%$ & f & $\%$ \\
\hline 1. Dor física impedindo você de fazer o que precisa & 9 & 8,8 & 3 & 5,9 & 6 & 11,8 \\
\hline 2. O quanto você aproveita a vida? & 84 & 82,3 & 46 & 90,2 & 38 & 74,5 \\
\hline 3. Em que medida sua vida tem sentido? & 95 & 92,2 & 49 & 96,1 & 46 & 88,4 \\
\hline 6. Satisfação com as relações pessoais & 84 & 82,4 & 43 & 84,3 & 41 & 80,4 \\
\hline 7. Satisfação com a vida sexual & 82 & 82 & 47 & 92,1 & 35 & 71,4 \\
\hline 8. Satisfação com o apoio recebido dos amigos & 85 & 82,5 & 44 & 86,3 & 41 & 78,6 \\
\hline 12. Avaliação de uma boa qualidade de vida & 91 & 89,2 & 45 & 88,3 & 46 & 90,2 \\
\hline
\end{tabular}

\section{DISCUSSÃO}

No desporto de alto rendimento, estímulos relacionados aos indicadores psicossociais e de qualidade de vida podem causar efeitos positivos ou negativos que influenciam diretamente o desempenho dos $\operatorname{atletas}^{20}$, uma vez que o desporto é construído socialmente ${ }^{21,22}$.

Os dados apresentados na tabela 1 mostraram que houve um equilíbrio quanto ao gênero dos participantes. A faixa etária dos indivíduos ficou compreendida no intervalo de 16 a 41 anos, sendo 95\% dos atletas distribuídos no intervalo etário de 18 e 30 anos. Em termos de tempo de prática dos atletas, 81,6\% praticavam modalidades específicas há mais de cinco anos, tempo considerado suficiente para a aquisição de experiências desportivas competitivas ${ }^{1,5}$. Quanto ao indicador nível de competição, houve uma predominância de participação nas competições nacionais (67,8\%). Além disso, 12 atletas (11,6\%) participaram em competições internacionais.

Os aspectos que designam união, tais como: penso que espírito de equipe é importante para alcançar vitórias (98\%) e gosto de trabalhar em equipe (95\%), são elementos coesivos e podem interferir no comprometimento individual em relação ao objetivo coletivo. Assim, atletas vistos pelos outros membros do grupo como individualistas, demonstrado na variável companheiro egoísta é um fator que provoca queda de desempenho da equipe (77,5\%), geram prejuízos à coesão e ao alcance das metas pré-definidas, ratificando os resultados encontrados em estudos ${ }^{1,8,13,15,23}$ sobre esta temática.

No que diz respeito às situações competitivas, ficar a frente do placar é algo motivador para ganhar o jogo $(73,8 \%)$ revelou ser um indicador significativo para a motivação. Em relação ao gênero, enquanto que os homens apontaram como fator mais representativo ficar a frente no placar é motivante (80,4\%), as mulheres destacaram trabalhar com técnico que só enxerga o lado negativo é desmotivante e prejudicial $(55,7 \%)$. Nessa ótica, observou-se que a motivação se refere aos indicadores ligados às variáveis sociais e/ou cognitivas que são utilizadas quando uma pessoa realiza uma tarefa na qual é avaliada ${ }^{5,8}$.

Quanto às atitudes individuais dos atletas, evidenciou-se uma tendência de auto-persuasão, demonstrada através de atitudes típicas do treino mental, como na assertiva antes da competição treino mentalmente o que planejo fazer no jogo (66\%), que vem se configurando como alternativa profícua para melhoria da auto-estima, autoconfiança, motivação e, consequentemente, resultando em eficácia elevada ${ }^{5,7,12,24}$. Houve similaridade das opções de respostas escolhidas entre os gêneros. Quando a análise se restringiu à autoconfiança, os atletas masculinos revelaram maior representatividade, pois ocorreu elevada incidência nas afirmações, tenho muito confiança nas minhas capacidades e habilidades atléticas (86,2\%); nos momentos decisivos sinto-me mais confiante para agir $(80,4 \%)$. Atletas que apresentam níveis significativos desse fator psicológico são mais propensos a obterem êxito desportivo ${ }^{11,12,14,16}$.

A auto-estima se revelou uma variável representativa, configurando um grupo de atletas com potencial para o sucesso no desporto, visto que mesmo em situações desfavoráveis de competição, ficar atrás no placar afeta a minha auto-estima (8,8\%), os mesmos preservam a percepção de que possuem 
auto-estima elevada. Estudos afirmam existir uma estreita relação entre autoconfiança, auto-estima e sucesso desportivo ${ }^{8,11,14}$.

Nos dados analisados sobre a variável concentração, foi percebida a habilidade dos atletas em não focar estímulos irrelevantes como a torcida influencia fortemente para me desconcentrar durante o jogo $(5,8 \%)$. Caso o desportista não se encontre concentrado para executar as ações que o levarão à vitória, outras qualidades que o mesmo possui diluem-se em meio ao complexo ambiente competitivo ${ }^{12,16,25}$.

Diversos atletas podem prejudicar suas equipes devido às lembranças de erros cometidos ${ }^{2}$, denotando o pensamento negativo como um fator inibidor de performance, demonstrado na assertiva costumo pensar e reviver os erros que cometi numa partida (55,3\%).

Os momentos que antecedem a competição foram identificados como importantes, no que concerne à ansiedade. Esse fato foi percebido nas afirmações sinto ansiedade enquanto espero o início do jogo $(60,8 \%)$ e antes de competir meu coração bate mais rápido que o normal (53,4\%). Embora alguns estudos ${ }^{6,9,11,25}$ confirmem tais evidências, esse fenômeno necessita ser analisado de forma cautelosa, pois conforme Schmidt ${ }^{26}$, a performance depende de um nível ótimo de ansiedade. Os resultados apresentados indicam um maior nível de ansiedade e menor autoconfiança entre as mulheres em relação aos homens ${ }^{6}$.

Ao ampliarem as análises para contemplar os fatores ambientais, algumas investigações ${ }^{1,2}$ identificaram aspectos desencadeadores de estresse semelhantes aos encontrados nesse estudo, reforçando a percepção de que perder jogos praticamente ganhos (75,7\%) e arbitragem prejudicial (81,4\%) estressam os atletas. Enquanto que no masculino houve similaridade nas indicações das respostas, no feminino elas recaíram na arbitragem $(92,1 \%)$ e no fato de repetir os mesmos erros $(88,2 \%)$. Houve diferença significativa entre os gêneros, revelando uma maior suscetibilidade das mulheres aos fatores causadores de estresse.

Quanto à categoria qualidade de vida, as situações mais representativas confirmaram uma relação de bem-estar, satisfação e estilo de vida saudável. Sob este olhar, o atleta que não detém qualidade de vida compromete o rendimento de sua equipe. Nesse estudo foram apontados indicadores que favorecem o desempenho desportivo, nomeadamente: boas relações pessoais (82,4\%), satisfação com a qualidade de vida $(89,2 \%)$ e ver sentido na vida (92,2\%).

Outra variável significativa dessa investigação foi a emoção, a qual está enraizada no próprio jogo.
Nas competições desportivas, as emoções afloram naturalmente, acometendo desportistas e espectadores. O envolvimento emocional é um poder catártico e mimético do desporto ${ }^{22,27,28}$. Ao considerar o gênero dos participantes, os dados foram bastante similares, havendo uma concordância de 70,5\% nas respostas do masculino e $73 \%$ para o feminino em relação à assertiva expressa minhas emoções quando sou bem sucedido nos momentos dos jogos.

No presente estudo, as limitações apresentadas foram: a escassez de pesquisas que relacionem qualidade de vida e aspectos sociais com o desempenho de atletas, o que dificultou a comparação dos achados dessa investigação. No que concerne às variáveis idade, modalidades desportivas e nivel de competição, os dados não foram discutidos de forma aprofundada devido à dispersão da distribuição das freqüências absolutas e relativas dos atletas segundo essas categorias analíticas.

Apesar das limitações observadas, acredita-se que este estudo preencheu uma lacuna na literatura quando analisou, concomitantemente, os aspectos psicossociais, a qualidade de vida, o treinamento e o rendimento desportivo, evitando a análise fragmentada das categorias analíticas que tem sido freqüente na literatura da área.

\section{CONCLUSÃO}

A partir do objetivo proposto e de acordo com os resultados encontrados, concluiu-se que a motivação, autoconfiança, auto-estima, concentração, emoção, treino mental e qualidade de vida satisfatória são deflagradores de performance, enquanto que as categorias estresse, medo do erro, pensamento negativo e ansiedade elevada são inibidoras.

Com o intuito de otimizar o rendimento desportivo, as intervenções técnicas são demandadas, tais como: reforços positivos; revisão dos pontos fortes pessoais e pontos fracos dos adversários; visualização das ações motoras; exercícios de relaxamento através da respiração; técnicas de meditação; diálogos destinados à repressão de sentimentos e pensamentos negativos; mudanças sistemáticas de métodos e locais de treinamento.

Por fim, na busca por identificar os aspectos psicossociais inerentes ao meio desportivo, esse artigo reforçou a importância do treinamento de atletas que contemple o homem nas suas múltiplas dimensões, não se restringindo apenas aos componentes físico, técnico e tático. Assim, os atletas que têm oportunidades de treinar sob a ótica humanista, na interação entre a tecnologia do treinamento 
e as necessidades sociopsicológicas, terão maiores possibilidades de sucesso na jornada desportiva.

\section{REFERÊNCIAS BIBLIOGRÁFICAS}

1. De Rose Junior D. Situações de jogo como fontes de "stress" em modalidades esportivas coletivas. Rev Bras Educ Fís Esp 2004;18(4):385-395.

2. De Rose Junior D, Deschamps SR. Situações causadoras de "Stress" no Basquetebol de alto rendimento: Fatores competitivos. Rev Paul Educ Fís 1999;13(2):217-229.

3. De Rose Junior D, Pereira FP. Situações especificas de jogo causadoras de "Stress" em oficiais de Basquetebol. Rev Paul Educ Fís 2002;16(2):166-173.

4. Rohlfs ICPM, Carvalho T, Rotta TM, Krebs RJ. Aplicação de instrumentos de avaliação de estados de humor na detecção da síndrome do excesso de treinamento. Rev Bras Med Esporte 2004;10(2):111-116.

5. Mahl AC, Raposo JV. Perfil psicológico de prestação de jogadores profissionais de futebol do Brasil. Rev Port Cien Desp 2007;7(1):80-91.

6. Dias CS. Do stress e ansiedade às emoções no desporto: da importância da sua compreensão à necessidade da sua gestão. [tese de doutorado - Instituto de Educação e Psicologia]. Braga (Portugal): Universidade do Minho; 2005.

7. Coelho RW, Oliveira S, Elsangedy HM, Krinski K, Colombo H, Buzzachera CF, et al. O efeito da imaginação no desempenho e na precisão do saque no tênis de campo. Rev Bras Cineantropom Desempenho Hum 2008;10(2):176-183.

8. Pujals C, Fiorese Vieira L. Análise dos fatores psicológicos que interferem no comportamento dos atletas de futebol de campo. Rev Educ Fís 2002;13(1):89-97.

9. Margis R, Picon P, Cosner AF, Silveira RO. Relação entre estressores, estresse e ansiedade. Rev psiquiatr Rio Gd Sul 2003;25(1):65-74.

10. Rubio K. O imaginário da derrota no desporto contemporâneo. Psicol. Soc. 2006; 18(1): 86-91.

11. Samulski DM. Suporte psicológico aos atletas brasileiros durante as olimpíadas de Atenas 2004. Rev Bras Educ Fís Esp 2006; 20(5):165-167.

12. Bray SR, Martin KA. The effect of competition on individual athlete performance and psychological states. Psychol Sport Exerc [periódico on line] 2003; 4. Disponível em <http://www.csub.edu/ isumaya/300/ article2.pdf $>$ [2007 Jan 15].

13. Bueno JLO, Di Bonifácio MA. Alterações de estados de ânimo presentes em atletas de voleibol, avaliados em fases do campeonato. Psicol Estud 2007;12(1):179-184.

14. Oliveira SRS, Serassuelo Junior H. Seleção paulista masculina de Judô: estudo do comportamento das tendências competitivas entre atletas federados. Rev Bras Cineantropom Desempenho Hum 2006;8(4):82-90.
15. Samulski DM. Psicologia do Esporte. São Paulo: Manole; 2002.

16. Stefanello JMF. Regulação dos níveis de ativação no Vôlei de praia de alto rendimento: um estudo de caso com campeões olímpicos. Rev Bras Cineantropom Desempenho Hum 2007;9(4):372-379.

17. Simões AC, De Rose Junior D. Psicossociologia como área de conhecimento da ciência do desporto. Rev Paul Educ Fis 2004;18:73-81.

18. Thomas JR, Nelson JK. Métodos de pesquisa em atividade física. $3^{\mathrm{a}}$ ed. Porto Alegre: Artmed; 2002.

19. Nahas MV. Atividade física, saúde e qualidade de vida, conceitos e sugestões para um estilo de vida ativo. $2^{\text {a }}$ ed. Londrina: Midiograf; 2001.

20. Vieira SL, Fernandes SL, Vieira JLL, Vissoci JRN. Estado de humor e desempenho motor: um estudo com atletas de voleibol de alto rendimento. Rev Bras Cineantropom Desempenho Hum 2008;10(1):62-68.

21. Costa, MM. Esporte de alto rendimento: produção social da modernidade - o caso do vôlei de praia. Soc. Estado 2007;22(1):35-69.

22. Barroso MLC, Krebs RJ. Fatores que geram violência no futebol: uma análise psicológica na região Sul do Brasil. Rev Bras Cineantropom Desempenho Hum 2007;9(2):154-158.

23. Weinberg RS, Gould D. Fundamentos da Psicologia do desporto e do exercício. $2^{\mathrm{a}}$ ed. Porto Alegre: Artmed; 2001.

24. Simões AC, Conceição PFM. Dinâmica e intervenção psicológica em uma equipe de voleibol masculina. Rev Bras Educ Fís Esp 2006;20(3):195-207.

25. Stoeber J, Otto K. Perfectionism and competitive anxiety in athletes: Differentiating striving for perfection and negative reactions to imperfection. Pers Individ Dif 2007;42(6):959-969.

26. Schmidt RA. Aprendizagem \& performance motora: dos princípios à prática. Tradução: Flávia da Cunha Bastos, Olívia Cristina Ferreira Ribeiro. São Paulo: Movimento, 1993.

27. Freitas CMSM, Santiago MS. Aspectos motivacionais que influenciam a adesão e manutenção de idosos a programas de exercícios físicos. Rev Bras Cineantropom Desempenho Hum 2007;9(1):92-100.

28. Elias N, Dunning E. A busca da excitação. Lisboa: DIFEL, 1992.

\section{Endereço para correspondência}

Clara Maria Silvestre Monteiro de Freitas

Rua Amazonas, 223, apt ${ }^{\circ}$ 802, Boa Viagem

CEP: 51011-020 - Recife, PE. Brasil.

E-mail: clarasilvestre@uol.com.br 